\section{Total RNA-Based Target Design for Microarray Analysis of Defined Tumor Areas}

\section{BioTechniques 32:744-748 (April 2002)}

Efficient gene expression analysis at the cellular level using microarrays requires the development and successful implementation of a variety of laboratory strategies. Major problems that have to be overcome are to efficiently obtain high-purity and quality RNA from limited amounts of neoplastic cells separated from contaminating normal cells and to perform linear and reproducible RNA amplification. Previous studies demonstrated that 50000-200000 cells (7) or $50 \mathrm{ng}$ to $1 \mu \mathrm{g}$ total RNA (5) are feasible for generating target samples for hybridization of microarrays for gene expression profiling.

We developed a concise guide to a total RNA-based target design for mi-

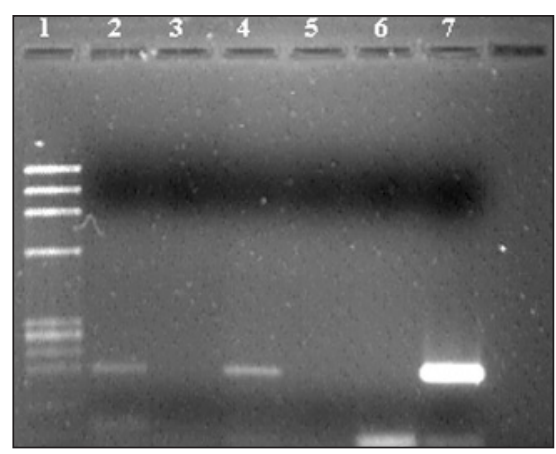

Figure 1. Control RT-PCR. RT-PCR amplification of a 326-bp cyclophilin fragment using primers (ams biotechnology, Wiesbaden, Germany) for this housekeeping gene transcript to control the quality of isolated total RNA. cDNAs were obtained from the total RNA from about 3000 microdissected tumor cells (sample A) and about 5000 microdissected tumor cells (sample B). Lane 1 indicates the molecular weight standard (Roche Applied Science, Mannheim, Germany). The RT-PCR results (35 cycles of amplification) are shown for sample A (3000 cells) in lane 2 and for sample B (5000 cells) in lane 4. Lane 7 indicates the amplification of a cyclophilin-positive control (ams biotechnology Germany). Lane 6 is the no-template control of this PCR. For both samples, A and B, a "no reverse transcription control" was performed (by omitting the reverse transcriptase enzyme in the RT step) to prove the absence of DNA in the total RNA samples. No cyclophilin amplification fragment is seen in this control experiment for both sample A (lane 3) and B (lane 5).

Table 1. Cell Separation: Staining and Fixation Protocol

1. Absolute ethanol fix for $1 \mathrm{~min}$.

2. Rehydrate by dipping in ethanol-DEPC-water (95\%-70\%-50\%).

3. Stain in hematoxylin for $15 \mathrm{~s}$ and dip in DEPC-treated water.

4. Stain in Blueing Reagent for $30 \mathrm{~s}$ and wash.

5. Stain in Eosin $Y$ for $10 \mathrm{~s}$ and wash.

6. Dehydrate by dipping in ethanol (50\%-70\%-95\%).

7. Dip in xylene for $1 \mathrm{~min}$.

8. Air-dry for $10 \mathrm{~min}$.

Table 2. Total RNA Isolation Protocol for Limited Amounts of Starting Material

1. Prepare a denaturation solution from the Micro RNA Isolation ${ }^{\mathrm{TM}}$ Kit (Stratagene, La Jolla, CA, USA), according to manufacturer's guidelines. Add $200 \mu \mathrm{L}$ solution per microdissection sample, invert carefully, and incubate $10 \mathrm{~min}$ at $37^{\circ} \mathrm{C}$ and 5 min on ice.

2. Add $20 \mu \mathrm{L} 2 \mathrm{M}$ sodium acetate, $220 \mu \mathrm{L}$ phenol, $60 \mu \mathrm{L}$ chloroform:isoamyl alcohol (equilibrated with succinic acid) to each sample (24:1), vortex mix for 30 $\mathrm{s}$, and incubate on ice for $5 \mathrm{~min}$. Centrifuge at maximum speed $(10000 \times \mathrm{g})$ for 8 min.

3. Remove the supernatant completely into a new tube. Add $1 \mu \mathrm{L}$ glycogen as a carrier and 3 volumes of $-20^{\circ} \mathrm{C}$ ethanol, mix slowly, and incubate for $20 \mathrm{~min}$ at $-20^{\circ} \mathrm{C}$.

4. Centrifuge at maximum speed for 30 min at $4^{\circ} \mathrm{C}$, wash the tiny pellet with $75 \%$ ethanol, centrifuge again for $6 \mathrm{~min}$, and air dry it at room temperature.

5. Resuspend the pellet in $16 \mu \mathrm{L}$ DEPC-treated water. Add $1 \mu \mathrm{L}$ RNasin ${ }^{\circledR}$ (Promega, Madison, WI, USA), $2 \mu \mathrm{L} 10 \times$ DNase I enzyme buffer, and $1 \mu \mathrm{L}$ DNase I. Incubate for $45 \mathrm{~min}$ at $37^{\circ} \mathrm{C}$.

6. Extract the RNA with an equal volume phenol:chloroform (1:1). Centrifuge at $3000 \times g$ for $10 \mathrm{~min}$ and repeat the extraction with chloroform:isoamyl alcohol $(24: 1)$. Note that if there is very little supernatant after phenol:chloroform extraction, then skip the chloroform:isoamyl alcohol extraction step.

7. Remove the supernatant completely into a new tube. Add $1 \mu \mathrm{L}$ glycogen as a carrier, 0.1 volume $3 \mathrm{M}$ sodium acetate, $\mathrm{pH} 5.4$, and 3 volumes $-20^{\circ} \mathrm{C}$ ethanol, mix slowly, and incubate for at least $30 \mathrm{~min}$ at $-70^{\circ} \mathrm{C}$.

8. After centrifugation for $10 \mathrm{~min}$ at maximum speed, wash the pellet twice in $70 \%$ ethanol, air dry it briefly, and resuspend it in $10 \mu \mathrm{L}$ DEPC-treated water.

croarray analysis of a defined tumor area such as the tumor-host-interface, which starts with only 3000-5000 cells. According to the recommended nomenclature, a "probe" is the tethered nucleic acid with known sequence, whereas a "target" is the free nucleic acid sample whose identity/abundance is being detected. Our protocol involves procedures that have been refined from recently published technologies and is addressed especially to laboratories that start in the field and face many existing methods. These guidelines should be applicable to all experimental conditions in which starting tumor material is the limiting factor, as in small biopsies, fine-needle aspirates, or microdissected tissue areas. Identification of differentially ex- pressed genes from defined tumor areas such as the tumor-host interface requires separating tumor and normal cells, thereby maintaining the tissue architecture and RNA integrity. The first important step is the surgical excision of cancer tissue and immediately snapfreezing under close to RNase-free conditions.

Several microscope systems for cell microdissection are available that mainly differ in the principle of how to capture the dissected cells. We tested different laser capture microscope systems, comparing the precision of the cutting laser, the mode of recovering the dissected areas, the handling of the software, and the quality of the image data. Traditional glass-mounted frozen 
Table 3. Target Sample Preparation

\begin{abstract}
First- and Second-Strand cDNA Synthesis
1. To initiate first-strand synthesis, use the SUPERSCRIPTTM Choice System (Invitrogen, Carlsbad, CA, USA). To $10 \mu \mathrm{L}$ total RNA (see Table 2), add $1 \mu \mathrm{L} 25 \mu \mathrm{M} \mathrm{T7}$-oligo (dT) ${ }_{15}$ primer (9), denature at $70^{\circ} \mathrm{C}$ for $5 \mathrm{~min}$, and anneal at $42^{\circ} \mathrm{C}$ for $3 \mathrm{~min}$. Add first-strand reaction buffer, DTT, dNTPs RNasin, $1 \mu \mathrm{L} 25 \mu \mathrm{M}$ template switch primer (9), and $1 \mu \mathrm{L}$ SUPERSCRIPT II reverse transcriptase, according to the manufacturer's instructions. Incubate for $1 \mathrm{~h}$ at $42^{\circ} \mathrm{C}$.

2. Perform second-strand cDNA synthesis with the Advantage ${ }^{\mathrm{TM}} \mathrm{CDNA}$ PCR Kit (BD Biosciences Clontech, Palo Alto, CA, USA), as described in Reference 9. Extract the resulting cDNA in two steps with phenol:chloroform:isoamyl alcohol and ethanol (25:24:1), resuspend it in $16 \mu \mathrm{L}$ DEPC-treated water, and wash it twice in a Microcon ${ }^{\mathrm{TM}}$ YM100 spin column (Amicon, Beverly, MA, USA).

\section{Transcription and Linear Amplification}

1. Perform transcription of the dsDNA into amplified RNA with the T7 Megascript ${ }^{\mathrm{TM}}$ Kit (Ambion, Austin, TX, USA), as described in Reference 9. Extend the incubation with T7 RNA polymerase to $10 \mathrm{~h}$ or overnight to improve the yield of RNA. Perform RNA recovery as described in our RNA isolation protocol, steps $6-8$, and resuspend the pellet in $15 \mu \mathrm{L}$ DEPCtreated water.

2. This amplified RNA is now the template for the next dsDNA synthesis with random hexamers in the first-strand synthesis and T7-oligo-(dT) primer in the second-strand synthesis, as described in Reference 9. Again, extract the resulting cDNA as above and use it as a template for the next transcription step into secondly amplified RNA with the T7 Megascript Kit. Perform RNA recovery as described in our RNA isolation protocol, steps $6-8$, and resuspend the pellet in $10 \mu \mathrm{L}$ DEPC-treated water.

\section{Labeling}

1. After denaturation of this RNA at $65^{\circ} \mathrm{C}$ for $5 \mathrm{~min}$, it was labeled in a RT reaction using $1.5 \mu \mathrm{L}$ nucleotides ( $2 \mathrm{mM}$ each) without dTTP, $1.2 \mu \mathrm{L}$ dTTP (2 mM), 1.5 $\mu \mathrm{L}$ Cy5-dUTP (Amersham Biosciences, Piscataway, NJ, USA), $6 \mu \mathrm{L}$ first-strand buffer (Invitrogen), $3 \mu \mathrm{L} 0.1 \mathrm{M} \mathrm{DTT}, 10 \mu \mathrm{L}$ random hexamer primer $(1 \mathrm{mg} / \mathrm{mL})$, and $2 \mu \mathrm{L}$ SUPERSCRIPT II enzyme. Alternatively, Cy3-dUTP can be incorporated. Incubate for $1 \mathrm{~h}$ at $42^{\circ} \mathrm{C}$, add another $1.5 \mu \mathrm{L}$ enzyme, and incubate again for $1 \mathrm{~h}$. Centrifuge briefly at $10000 \times g$ and add $0.5 \mu \mathrm{L} \mathrm{RNase} \mathrm{H}(5 \mathrm{U} / \mu \mathrm{L})$. Incubate for $20 \mathrm{~min}$ at $37^{\circ} \mathrm{C}$.

2. Purify the labeled cDNA by washing twice with DEPC-treated water in a Microcon YM30 spin column.
\end{abstract}

tissue samples were compared to membrane-mounted specimens. The best results were obtained with a "cut and catapult" system that combines the laser microbeam dissection with laser pressure catapulting. This system enables the separation of defined tumor areas from normal cells under optical control and the contact-free sterile transfer of the dissected material without encroachment of adjacent areas. Tissue sections $(7-8 \mu \mathrm{m})$ mounted on a supporting membrane should be used. This membrane maintains tissue architecture and supports the dissection and catapulting of larger cell areas.

For microdissection, an optimized staining and fixation protocol is needed that provides acceptable morphology, despite the optical losses from stained frozen sections without coverslips, and preserves the RNA integrity $(3,4)$. Different results were obtained depending on the tissue mounting, fixatives, and staining procedure, and an optimized staining protocol was developed (Table 1).

A primary limitation of any target design for microarray hybridization is the amount of total RNA or poly(A) RNA that can be obtained from small samples. Despite the many previously published RNA isolation procedures that all promise high yields of pure intact RNA, we feel the quantity and quality of RNA isolated from very few microdissected cells to be the major technical obstacle. In an effort to reduce the amount of

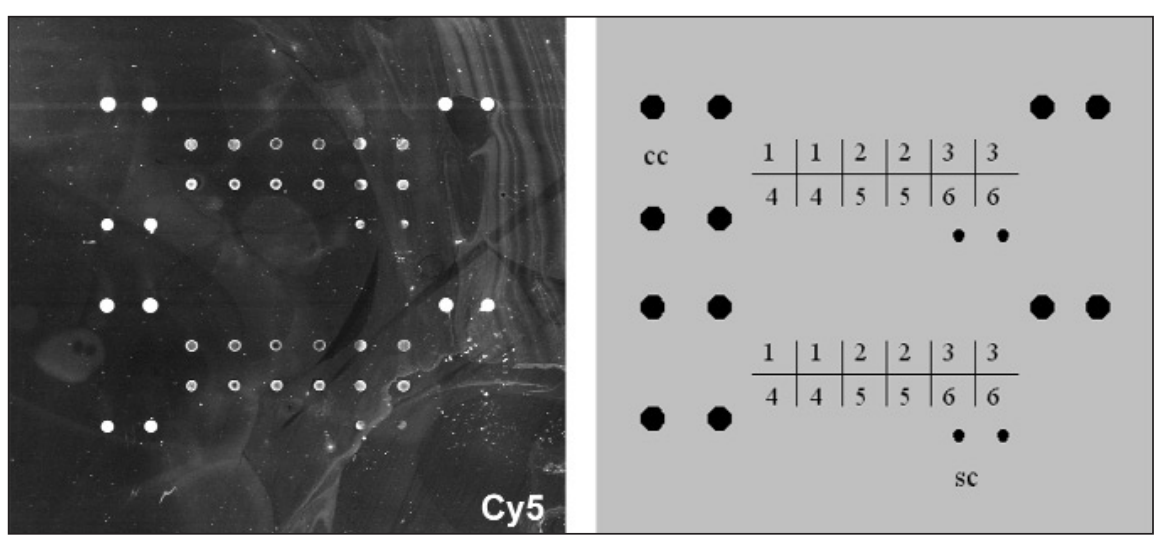

Figure 2. Control array hybridization. Quality control of the total RNA-based Cy5 fluorescently labeled cDNA target in array hybridization (left). These inexpensive control arrays contain five human housekeeping gene probes (numbers 1-5) and staining (sc) and coupling (cc) controls, as indicated schematically (right). The control gene transcripts are glyceraldehyde-3-phosphate (GAPDH) (1), $\beta$ actin (2), ribosomal protein 7 (3), porphobilinogen deaminase (PBGD) (4), and histone 3a (5); number 6 is the manufacturer's internal hybridization control (GeneScan Europe). 
inants and eluting bound total RNA or on (ii) cell lysis with guanidinium thiocyanate and phenol:chloroform:isopropanol extraction, and we tried (iii) to produce first-strand cDNA directly from cell lysates, thereby eliminating the RNA isolation step.

In our experiments with as few as about 3000 microdissected cells, we were not able to perform RT-PCR directly from cell lysates without initial RNA isolation. We could not confirm the successful results obtained with the widely used silica-gel binding RNA isolation procedures $(5,8,9)$. In our experiments with only 3000 cells, these methods based on matrix binding did not give satisfying total RNA recovery rates in the elution step, and DNA contamination was found in control RT-PCRs without adding reverse transcriptase, possibly because of an insufficient oncolumn DNase digestion. In the original protocols based on phenol:chloroform: isopropanol extraction, it was impossible to precipitate sufficient yields of pure undegraded RNA from the aqueous layer because of the limited initial amount of cells. Therefore, we developed an optimized protocol that combines a guanidinium thiocyanate-based denaturation with a modified RNA precipitation and purification protocol (1), as shown in Table 2 . The quality of the isolated DNA-free total RNA was examined by RT-PCR (Figure 1).

Generating target samples from small microdissected sections suitable for hybridization of microarrays requires linear RNA in vitro amplification. We used a modified T7 RNA polymerase linear amplification protocol $(2,6)$ combined with a templateswitching mechanism (9), as described in detail in Table 3, which also indicates changes to the original protocols.

To prove the quality and efficiency of our labeled target, ArrayLink ${ }^{\mathrm{TM}}$ control slides (GeneScan Europe, Freiburg, Germany) were hybridized according to the manufacturer's protocol. Briefly, arrays were prehybridized with GeneScan hybridization solution containing $1 \mu \mathrm{g}$ salmon sperm DNA and washed in $2 \times$ SSC buffer. Hybridization was performed overnight at $37^{\circ} \mathrm{C}$ with $5 \mu \mathrm{L}$ labeled cDNA in $20 \mu \mathrm{L}$ hybridization solution, follwed by three washing steps with SSC/0.1\% SDS buffer. Cy5-fluorescence signals can be seen for all housekeeping gene transcripts (Figure 2).

\section{REFERENCES}

1.Dyanov, H.M. and S.G. Dzitoeva. 1995. Isolation of DNA-free RNA from a very small number of cells. BioTechniques 18:558-564.

2.Eberwine, J., H. Yeh, K. Miyashiro, Y. Cao, S. Nair, R. Finnell, M. Zettel, and P. Coleman. 1992. Analysis of gene expression in single live neurons. Proc. Natl. Acad. Sci. USA 89:3010-3014

3.Fend, F., B.M. Emmert, R. Chuaqui, K. Cole, J. Lee, L.A. Liotta, and M. Raffeld. 1999. Immuno-LCM: laser capture microdissection of immunostained frozen sections for mRNA analysis. Am. J. Pathol. 154:61-66.

4.Goldsworthy, S.M., P.S. Stockton, C.S. Trempus, J.F. Foley, and R.R. Maronpot. 1999. Effects of fixation on RNA extraction and amplification from laser capture microdissected tissue. Mol. Carcinog. 25:86-91.

5.Gonzalez, P., J.S.J. Zigler, D.L. Epstein, and T. Borras. 1999. Identification and isolation of differentially expressed genes from very small tissue samples. BioTechniques 26:884-892.

6.Luo, L., R.C. Salunga, H. Guo, A. Bittner, K.C. Joy, J.E. Galindo, H. Xiao, K.E. Rogers, et al. 1999. Gene expression profiles of laser-captured adjacent neuronal subtypes. Nat. Med. 5:117-122.

7.Mahadevappa, M. and J.A. Warrington. 1999. A high-density probe array sample preparation method using 10 - to 100 -fold fewer cells. Nat. Biotechnol. 17:1134-1136.

8.Ohyama, H., X. Zhang, Y. Kohno, I. Alevizos, M. Posner, D.T. Wong, and R. Todd. 2000. Laser capture microdissection-generated target sample for high-density oligonucleotide array hybridization. BioTechniques 29:530536.

9.Wang, E., L.D. Miller, G.A. Ohnmacht, E.T. Liu, and F.M. Marincola. 2000. High-fidelity mRNA amplification for gene profiling. Nat. Biotechnol. 18:457-459.

We thank Drs. U.P. Rausch and S. Mauch (GeneScan Europe) and Dr. R. Ehricht (CLONDIAG ${ }^{\circledR}$ Chip Technologies GmbH, Jena, Germany) for technical advice. Address correspondence to Dr. Regine Dahse, Klinikum der FSU Jena, Institut für Humangenetik und Anthropologie, Kollegiengasse 10, D-07740 Jena, Germany. e-mail: rdah@mti-n.uni-jena.de

Received 20 August 2001; accepted 28 January 2002.

Regine Dahse, Alexander Berndt, and Hartwig Kosmehl Friedrich-Schiller-University Jena

Germany

\section{SNP Analysis by Allele- Specific Extension in a Micromachined Filter Chamber}

BioTechniques 32:748-754 (April 2002)

Single-nucleotide polymorphisms (SNPs) are distributed across the genome with an estimated prevalence of 1 SNP per 1300 bases $(4,12)$ and hence are useful as genetic markers in linkage studies, pharmacogenomics, forensics, and the analysis of loss of heterozygosity. Consequently, the high prevalence of SNPs throughout the genome requires efficient methods to analyze these sequence variants. Several high-throughput techniques are now available for this purpose. Many of the methods use allele-specific hybridization to discriminate between allelic variants. These methods include allelespecific hybridization in microarray formats (13), molecular beacons (11), dynamic allele-specific hybridization (3), and TaqMan ${ }^{\circledR}$ PCR amplification (5). Some other widely used genotyping technologies are minisequencing (8) and ligation assays (7). Allele-specific amplification (6) and extension (9) have also been used for the analysis of genetic variations.

A recently developed technique for SNP genotyping is pyrosequencing (1). The technique relies on the incorporation of nucleotides by DNA polymerase and the release of pyrophosphate $\left(\mathrm{PP}_{\mathrm{I}}\right)$, which will be converted to ATP and then to detectable light by sulfurylase and luciferase, respectively (10). In the standard procedure of pyrosequencing, iterative addition of dNTPs is performed, and as the process continues, the complementary DNA strand is built up and the sequence is determined. In an alternative approach (for SNP analysis), allele-specific extension with alternating $3^{\prime}$ end primers and the addition of all four nucleotides may be utilized. The direct consequence of this approach will be that the DNA polymerase fully extends a complete matched primer-template, and an equivalent amount of $\mathrm{PP}_{\mathrm{I}}$ will be released. If the primer-template does not match at the $3^{\prime}$ end of the primer, then 